\title{
The technique of construct water-saving agriculture
}

\author{
$\mathrm{REN} \mathrm{Ji}^{1}$ \\ ${ }^{1}$ Zhejiang Design Institute of Water Conservancy and Hydroelectric Power, Hangzhou, Zhejiang, 310002
}

\begin{abstract}
A shortage of water resource in China, the water problem has become the bottleneck of China's economic and social development. Agriculture consumes very large amounts of water resources and water waste is quite serious in our country, therefore, the construction of water-saving agriculture is urgent to solve the problem of water resource in our country. Implementation technology in the construction of water-saving agriculture was proposed in this paper, namely improve the canal water use coefficient, water saving irrigation methods and suitable irrigation mode.
\end{abstract}

\section{Introduction}

China is a country with a shortage of water resources, and its per capita water resources only account for one quarter of the world average. Social and economic water security has become an important factor restricting China's social and economic development. Also, it comes to be an urgent problem in current social and economic development. At the same time, our country is an agricultural country, agricultural irrigation water consumption accounts for $80 \%$ of the total water consumption, and canal water use coefficient is only 0.5 , using the flood irrigation method, the utilization rate of water is only $30 \sim 40 \%$. Therefore, the development of agricultural water-saving irrigation technology is a solution of water shortage and waster.

\section{Water-saving agricultural technical measures}

The development of water-saving agriculture has a broad connotation. It includes several aspects, such as the rational development and utilization of water resources and configuration, water saving in the water transportation and distribution system, moisture field water-saving irrigation process, water saving in crop growth process, water saving in water management, and agronomic water-saving technical measures to increase production, etc.

From the perspective of water use, agricultural irrigation is to meet the needs of crops by supplying water to the farmland, to create good environmental conditions for crop growth, so as to obtain higher yields. Water is transported from water source to crop yields through the following four processes: (1) Using channels or pipelines to transform the water from the source to the field, this process known as hydro. (2) The irrigation water that is brought into the field, it is distributed as evenly as possible to the designated area and converted into soil water. (3)Crops attach to absorbing and utilizing soil and water to maintain their physiological activities. (4) The economical yield is formed through the complex physiological process of crops. It can be seen that all kinds of measures can be adopted in different links to achieve the effect of water saving. At the same time, through the storage of soil moisture, to create a suitable environment for water, fertilizer, gas and heat in the root soil of crops, to obtain the high yield and good quality. Therefore, the measures, techniques and methods that can reduce water loss, improve water utilization rate and water productivity belong to the research scope of this paper. The first two processes have great water-saving potential, which are two of the main ways to save water. The remaining two processes are mainly aimed at how to achieve the effect of increasing production under the condition of water saving. The existing research results show that the application of the new technology of water saving and the suitable irrigation model has a good effect on increasing water productivity. Accordingly, the technical idea of constructing water-saving agriculture is to take corresponding measures in the four processes of irrigation water, so as to achieve the purpose of saving water and increasing production.

\subsection{Water-saving technology in hydrophobic process}

During the hydrophobic process, the loss of water is mainly reduced, that is, the utilization coefficient of canal system water is increased. The utilization coefficient of the canal system mainly depends on the soil quality and hydrogeological conditions, engineering conditions, management level and irrigation area scale. In general, the higher management level and smaller irrigation area can produce a higher canal water use coefficient. But for a fixed irrigation area, the size of its channels, soil and hydrogeological conditions are determined. The water 
utilization coefficient of the drainage system can be improved as follows:

\subsubsection{Increase the slope of the channel}

The higher the slope of the channel and the velocity, the faster the same amount of water reaches the field, the smaller the leakage and the higher the water utilization coefficient of the canal system.

\subsubsection{Using anti-seepage measures}

The channel seepage prevention technology can reduce the loss of the channel seepage effectively, improve the utilization rate of agricultural water and make more effective use of water resources. The commonly used anti-seepage materials include concrete, masonry, film materials, soil-cement, etc.

Brew with concrete lining channel is a kind of seepage control technology that is now widely used. Its seepage control effect is better than that of other seepage control measures, which can reduce leakage by $90 \%$ $95 \%$. It has high anti-seepage intensity, small and rough rate, allowing high flow velocity, but the cost is high. The advantage of masonry seepage prevention is that it can use local materials and has strong resist erosion and wear resistance. Generally, the flow velocity of canal can reach $3.0 \mathrm{~m} / \mathrm{s} \sim 6.0 \mathrm{~m} / \mathrm{s}$, which is greater than the concrete seepage control channel. Secondly, the anti-freezing and anti-seepage ability is also strong, and this method is suitable for the channel with rich source of stone and the requirements of anti-freezing and washing. The use of film material anti-seepage has a better effect, which can reduce about $90 \%$ of the leakage loss. When using soil as protective layer, the cost is lower, but need more area and allows small velocity, which is suitable for small and medium low velocity of flow channel. When using rigid protective layer, the cost is high, suitable for large and medium irrigation areas. Soil material anti-seepage is a simple technology and low cost anti-seepage technology, which can be used locally and is easy to construct. Therefore, it only applies to medium and small channels in temperate regions. The selection of impermeable materials should be based on the actual situation of irrigation area.

\subsubsection{Using pipe drain}

Pipelines are directly decorated in the irrigation area, the canal water use coefficient can reach above $0.8 \sim 0.9$. Compared with the soil canal irrigation, the pipe drain will reduce $30 \sim 40 \mathrm{~m}^{3}$ of the average gross irrigation water per $\mathrm{mu}, 10 \%$ of the channel area, $30 \% \sim 40 \%$ of the water consumption. The surface irrigation system of low pressure pipeline is applied to irrigation area rapidly with the advantages of saving water $(30 \%)$, saving land $(7 \% \sim 13 \%)$, low cost, rapid water transfer and easy management.

\subsection{Water-saving irrigation techniques}

China basically uses the flood irrigation, which needs a large amount of water, and the irrigation effect is not ideal and the waste is serious. In recent years, water-saving irrigation technology has been paid more and more attention due to the understanding of water resources. Some widely used saving irrigation techniques are briefly introduced:

\subsubsection{Improved surface irrigation technology}

Surface irrigation will remain the main irrigation method in China for a long time. Surface irrigation is not "flood irrigation with large water". As long as reasonable irrigation technology is adopted and management is strengthened on the basis of land leveling, the utilization rate of water in the field can reach more than $70 \%{ }^{[2]}$. For example, Laser controlled ground leveling technology, improvement of radon (ditch) irrigation technology, field sluice irrigation technology, wave surge technology and membrane technology can be applied to different irrigation areas. The effect of saving water and increasing production is also quite obvious.

\subsubsection{Spray irrigation}

Spray irrigation is to use special equipment to deliver pressurized water to irrigation area, irrigation equipment will have pressure and the water will spray into the air into small water droplets, evenly spread to the ground for irrigation. It is a kind of mechanized and efficient water-saving irrigation technology, which has the characteristics of water-saving, labor saving, land saving, highly yield and adaptability. It is widely used all over the world. Spray irrigation does not require the ground level, and is applicable to all kinds of topography, especially in places where the terrain is complex and the soil water permeability is large. Spray irrigation is applicable to almost all large field crops except rice, as well as vegetables, fruit trees. It has strong adaptability to topography, soil and other conditions. Compared with surface irrigation, field crop spray irrigation can generally save $30 \%-50 \%$ of the water ${ }^{[1]}$ and increase yield by $10 \%-30 \%$. It can also play a role in cooling, humidifying and regulating the microclimate in the field. However, it is not suitable to be used in windy conditions due to high energy consumption and investment.

\subsubsection{Drip irrigation technology}

Drip irrigation technology uses drip head, which usually on the dry pipe, branch pipe and wool pipe, to drip water slowly to the soil under low pressure. It is an irrigation system that supplies soil directly with filtered water, fertilizer, or other chemicals. It does not spray water or have channel water, just allows water to drip out slowly and enter the soil under the action of gravity and capillaries. Water is dripped into the soil near the root of the crop, so that the soil in the main root area of the crop is always the best water-bearing condition. This is an advanced irrigation method. It has the advantages of saving water, which is $35 \sim 75 \%$ less than sprinkler 
irrigation, saving labor, increasing production and increasing income. However, drip irrigation system has the disadvantages of high cost, easy blockage and unequal irrigation, so it is difficult to promote large areas.

\subsubsection{Seepage irrigation technology}

The irrigation methods mentioned above are collectively referred to as overland irrigation. Seepage irrigation is an underground irrigation technology. Seepage irrigation is the direct input of water, fertilizer and gas into the soil in the root region of the crop through a special seepage pipe embedded in the ground and under certain osmotic pressure and soil capillaries. Seepage irrigation technology shortens the process of irrigation. It directly sends water and fertilizer into the underground root zone through the seepage pipe.

The advantages of seepage irrigation are: no water on the surface, no soil consolidation, good air permeability, improvement of ecological environment, fertilizer saving, etc. The statistical data show that the utilization rate of seepage irrigation water can reach $95 \%$, which is respectively $75 \%$ and $25 \%$ less than that of basin irrigation and Spray irrigation. However, due to seepage irrigation technology is buried pipelines underground, so it is easy to jam, and cleaning and maintenance is very difficult. Moreover, seepage irrigation belongs to regional irrigation, which need appropriate embedding depth. If not, water and fertilizer may flow into the soil layer without root, which will cause the waste of water. Therefore, seepage irrigation technology needs further improvement.

\section{Crop irrigation model}

Each crop has its own characteristics of water consumption, based on the understanding of the relationship between the various stages of crop growth and water consumption, through appropriate irrigation model, supplemented by the correct agricultural technical measures, that is to achieve high yield, high quality and water saving purposes. This is a way to achieve water-saving purposes from the characteristics of the crops.

\subsection{Water-saving irrigation model of rice}

It is found that under the condition of ensuring normal growth and development of rice, the suitable combination of soil moisture or water level, upper and lower limit irrigation index and a proper amount of irrigation and water supply can promote and control the root system and plant growth of rice by regulating the coordination of water, gas, heat and nutrients in the soil. Meanwhile, it can help reduce ineffective water consumption and obtain water saving under high yield. The irrigation methods based on above researches include control irrigation, control irrigation with shallow moisture, control irrigation with light dew, irrigation with shallow moisture, irrigation with leaf age and incomplete irrigation. These models can save water by $10 \%$ to $50 \%[3]$, and increase production by $10 \%$ or so. Some models can improve the quality of rice.

\subsection{Water-saving irrigation mode of drought crop}

Current research and application of the drought crop water-saving irrigation models are inadequate irrigation, deficit adjustment irrigation, controlled alternate root irrigation and so on. The research needs to be further deepened.

In addition, development of eco-friendly water-saving and efficient irrigation technology model, real-time monitoring of water quality and water quality of irrigation system in digital irrigation area, closed-loop automatic control system for water management, measurement of irrigation area scale and decision support for real-time irrigation Research on holding system, compensation mechanism of water-saving agriculture and its economic, social and environmental response models is started.

\section{Conclusion}

This paper mainly describes how to achieve water-saving agriculture technically, which is the key to achieve water-saving agriculture. However, the meaning of the construction of water-saving agriculture is quite widespread. In addition to solve technical problems, it still needs to be improved in areas such as management measures. Meanwhile, with the emergence of a new concept of harmonious coexistence between man and nature, the coordinated development of agriculture and ecological environment should be fully considered in the future research of water-saving agriculture innovation, so as to promote the sustainable development of agriculture in China.

\section{References}

1. G. Yuanyu. Farmland Water Science. Beijing: China Water Resources and Hydropower Press, (1985)

2. Anonymity. Agricultural water-saving irrigation technology, Biological library, (2006)

3. P. Shizhang. In the construction of water-saving society thinking of agricultural water saving, Irrigation and drainage development center in China, (2006)

4. L. Xinjian. Importance of basic research for water-saving irrigation and study for establishment of water-saving society. China Water Resources, China Water Conservancy Press , (2018) 